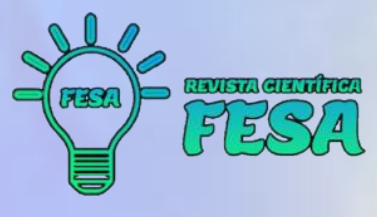

\title{
UTILIZAÇÃO DA LEI 8666/93 PELOS ORGÃOS PÚBLICOS
}

\author{
Gabriel Henrique Pagamisse Maximiano ${ }^{1}$
}

\section{RESUMO}

O presente artigo tem como finalidade analisar o regime licitatório no governo brasileiro, observando algumas de suas modalidades, assim como de suas aplicações na Administração Pública. Com a lei 8958/94, obteve-se um novo modelo de licitações, exercitáveis apenas por poucas instituições, que buscava também verificar a contratação por tempo determinado e as instituições sem fins lucrativos. Para a realização deste artigo, foi feita uma revisão bibliográfica acerca do assunto, que mostrou que o modelo de licitação trouxe diversas melhorias para a ordem jurídica no Brasil, como exemplo tem-se uma maior transparência entre as concorrências visando uma maior eficiência e a escolha das melhores propostas, dessa forma garantindo os princípios da eficiência, legalidade, impessoalidade, moralidade, publicidade.

Palavras-Chave: Licitações. Custo. Benefício.

\begin{abstract}
This article aims to analyze the bidding regime in the Brazilian government, observing some of its modalities, as well as its applications in Public Administration. With Law 8958/94, a new bidding model was obtained, which could only be exercised by a few institutions, which also sought to verify contracting for a fixed period and non-profit institutions. To carry out this article, a literature review on the subject was carried out, which showed that the bidding model brought several improvements to the legal order in Brazil, for example, there is greater transparency between competitions, aiming at greater efficiency and choice of the best proposals, thus guaranteeing the principles of efficiency, legality, impersonality, morality, publicity.
\end{abstract}

Keywords: Bids. Cost. Benefit.

\section{RESUMEN}

Este artículo tiene como objetivo analizar el régimen de licitación en el gobierno brasileño, observando algunas de sus modalidades, así como sus aplicaciones en la administración pública. Con la ley 8958/94, se obtuvo un nuevo modelo de licitación, ejercido sólo por unas pocas instituciones, que también buscaban verificar la contratación por un tiempo determinado y las instituciones sin fines de lucro. Para la realización de este artículo, se realizó una revisión bibliográfica sobre el tema, que mostró que el modelo de licitación trajo varias mejoras al ordenamiento jurídico en Brasil, como ejemplo hay una mayor transparencia entre los concursos con el objetivo de una mayor eficiencia y la elección de las mejores propuestas, asegurando así los principios de eficiencia, legalidad, impersonalidad, moralidad, publicidad.

Palabras clave: Pujas. Costo. Beneficio.

\footnotetext{
${ }^{1}$ Licenciado em Matemática, Geografia e História, especialista em Gestão escolar, TEA, Metodologia do Ensino de Química e Física. E-mail: Pagamax@gmail.com
} 


\title{
INTRODUÇÃO
}

Nas situações de compras de bens e serviços, existe a necessidade da manutenção de uma estrutura pré-definida, onde todos os responsáveis pela realização de compras sigam cada uma dessas etapas logísticas anteriormente estabelecidas. A lei 8666/93 auxilia na prevenção, manutenção e uso consciente dos orçamentos com destinação a bens e serviços públicos. Este é um assunto complexo e com várias vertentes de interpretação, pois a influência comercial e política interfere na economia, na sociedade e no poder público, devendo ser tratado de maneira calculada para que seja mantido o direito do contribuinte, e para que não haja desperdício de dinheiro público, conforme redação dada pela lei 8666/93:

\begin{abstract}
Art. 3 A licitação destina-se a garantir a observância do princípio constitucional da isonomia, a seleção da proposta mais vantajosa para a administração e a promoção do desenvolvimento nacional sustentável e será processada e julgada em estrita conformidade com os princípios básicos da legalidade, da impessoalidade, da moralidade, da igualdade, da publicidade, da probidade administrativa, da vinculação ao instrumento convocatório, do julgamento objetivo e dos que lhes são correlatos. (BRASIL, LEI 8666/93).
\end{abstract}

A legislação brasileira apresenta regras a serem seguidas para que haja um padrão nas aquisições definidas em licitações. Lembrando que a lei no 8.666/93, que resguarda o art. 37 da Constituição em seu inciso XXI, funda normas para que a Administração Pública possa realizar qualquer tipo de compra.

Todo tipo de compra realizada por um agente do Poder Público deve ser feito por meio de licitação, e esta deve observar as determinações do art. 37 caput e inciso XXI da Constituição Federal:

Art. $37 \mathrm{~A}$ administração pública direta e indireta de qualquer dos Poderes da União, dos Estados, do Distrito Federal e dos Municípios obedecerá aos princípios de legalidade, impessoalidade, moralidade, publicidade e eficiência e, também, ao seguinte:[...]

XXI- Ressalvados os casos específicos na legislação, as obras, serviços, compras e alienações serão contratados mediante processo de licitação pública que assegure igualdade de condições a todos os concorrentes, com cláusulas que estabeleçam obrigações de pagamento, mantidas as condições efetivas da proposta, nos termos da lei, o qual somente permitirá as exigências de qualificação técnica e econômica indispensáveis à garantia do cumprimento das obrigações. (BRASIL, 1988) 
O intuído deste projeto é demonstrar as metas e composições a serem seguidas pela Administração Pública para utilizar a licitação da maneira correta, assim como mostrar as prerrogativas legais e a vista da contratação.

O índice de não conhecimento dos processos padrões exigidos para a impetração de uma licitação influencia na solicitação de contratos não uteis ou sem necessidade, deixando de observar fatores importantes como a documentação das prestadoras do serviço. Nota-se que as licitações agem ligadas as questões orçamentárias, devendo ser vistas como importantes para o controle da verba pública, o que é fundamental para escolha de empresas e geração de rotação de capitais.

\section{ESTUDO DO CASO}

Como conjunto de abordagens técnicas para a realização deste trabalho, foi a busca por uma pesquisa aplicada, para que os conhecimentos obtidos sejam utilizados visando a solução dos problemas citados sobre o processo licitatório.

O objeto da pesquisa foi a pesquisa exploratória, a partir de levantamentos da legislação vigente, como a lei no 8.666/93.

Foi realizada também uma revisão bibliográfica sobre o tema dos processos licitatórios nas plataformas Google Acadêmico e Portal de Periódicos da Capes/MEC, nas quais encontrei textos como os de Daniele Meurer Ferreira (2013) e Daniela Cerri Junqueira (2013), que proporcionaram maior conhecimento sobre o procedimento licitatório, seus princípios, objetivos, características, modalidades, fases, aspectos criminais e contratos. Para realizar este trabalho, encontrei 644 trabalhos, porém apenas 2 se encaixam na proposta deste artigo, os artigos tratam das licitações para compra de bens móveis e imóveis para a administração pública, baseados na lei 8666/93. Ambos os trabalhos citam e exemplificam o artigo $7^{0}$ da lei, onde cita a logística para realização de uma licitação.

Também realizei pesquisa de campo, analisando e consultando material de órgãos público onde realizei verifiquei como dois órgãos do mesmo estado, porém de pastas diferentes realizavam as mesmas atividades para verificar qual agia de maneira mais eficaz

Este trabalho abordará, dentro do campo da Administração Pública, o papel das licitações para o equilíbrio e a nitidez do processo, mostrando claridade 
nos gastos públicos como uma ferramenta de gerenciamento das contas públicas para adquirir a proposta mais vantajosa e para que a qualidade seja sempre alcançada com o preço justo. Isso coíbe a utilização da máquina pública para proveito dos próprios dos agentes públicos e dinamiza o uso da forma correta, a bem do coletivo.

Para Daniela Cerri Junqueira (2013), a alienação de bens, na administração pública, se dará ao interesse público, justificada por meio de projeto básico. Após aprovada, deverá seguir as normas vigentes na lei nº 8.666/93, que regulamenta e padroniza os procedimentos para a realização de licitações na administração direta. A autora mostra a existência de diferenças entre aquisição de bens imóveis e móveis, uma vez que para o imóvel a aquisição se dará apenas após a autorização do legislativo, além da avaliação para verificação da licitação, onde deve ser comprovada a concorrência.

\begin{abstract}
Licitação é o procedimento administrativo destinado a selecionar, entre fornecedores qualificados, aquele que apresentar proposta mais vantajosa para a Administração. Regem a licitação os princípios de igualdade, da probidade administrativa, da vinculação ao edital, do julgamento objetivo, da legalidade, da impessoalidade, da moralidade e dos que lhe são correlatos. (ANGÉLICO, p. 80, 1994).
\end{abstract}

Nota-se que para os autores, que a licitação é dada pela Constituição Federal de 84, deixando-as limitadas a seguir os termos da lei 8666/93, como regras a serem seguidas para seleção da melhor proposta para o caso, dentre as disponibilizadas em editais especiais. A função de fiscalização cabe a sociedade e a administração pública, para proporcionar a legalidade e a transparência do processo licitatório.

Para Daniela Cerri Junqueira (2013) que coloca também a modalidade licitação dispensável:

Licitação dispensável é aquela cuja realização, nas hipóteses legais, fica a critério puramente discricionário da Administração Pública competente, em virtude de peculiaridade de seu objeto e/ou de outros elementos circunstanciais que envolvam a sua realização. As hipóteses estão elencadas no artigo 24 da Lei de Licitações, conforme segue:

"Art. 24 É dispensável a licitação:

I- para obras e serviços de engenharia de valor até 10\% (dez por cento) do limite previsto na alínea "a", do inciso I do artigo anterior, desde que não se refiram a parcelas de uma mesma obra ou serviço ou ainda para obras e serviços da mesma natureza e no mesmo local que possam ser realizadas conjunta e concomitantemente; 
II- para outros serviços e compras de valor até $10 \%$ (dez por cento) do limite previsto na alínea "a", do inciso II do artigo anterior e para alienações, nos casos previstos nesta Lei, desde que não se refiram a parcelas de um mesmo serviço, compra ou alienação de maior vulto que possa ser realizada de uma só vez;

III- nos casos de guerra ou grave perturbação da ordem. (JUNQUEIRA, 2013)

Para Daniele Meurer Ferreira (2013), a licitação se limita ao poder público em poder adquirir bens e serviços, utilizando as prerrogativas da lei 8666/93, visando a compra de produtos ou contratação de serviços com o melhor preço, visibilizando verbas públicas.

Garcia (2010) defende ainda que as licitações devem estar vinculadas ao processo licitatório decorrente a necessidade do poder público e devem deixar o processo mais justo para empresas pequenas, já que em seu trabalho está exposto que empresas grandes conseguem melhores licitações em seus contratos, já que possuem melhores condições de apresentação de produtos com o melhor preço.

De acordo com os estudos propostos por Dalmo Azevedo (2014) o conceito de licitação é de um procedimento administrativo seletivo, onde o objetivo é a aprovação da proposta mais vantajosa e, por obrigatoriedade, a administração pública direta e indireta devem obedecer aos art. 37, XXI e o art. 173 § 1ํㅡ, ambos da Constituição Federal de 1988, onde as autarquias e empresas públicas se aproveitam desta lei para controlar os contratos administrativos. De outra forma, podemos citar abaixo um tipo de processos que podem ocorrer em um processo licitatório sendo um processo administrativo, ou seja, uma sequência lógica de processos a serem seguidos; deve estar vinculado e deve ser seletivo, atendendo ao que se aplica a lei.

Muitos tem a velha mania de crer que para criar uma licitação, a previsão do Art. 37, que determina a obrigatoriedade de licitação para qualquer tipo de obra, serviço, bens etc.

Para Evandro Guedes (2015), diz que a regra geral deve ser aplicada a toda administração direta; UNIÃO, ESTADOS, Distrito Federal e MUNÍCIPIOS, além da administração indireta, com autarquias, fundações públicas, sociedades de economia mista e as empresas públicas. Guedes ainda alega que existem exceções para este tipo de processo, exemplificando a PETROBRÁS, que por

\section{CONERGÉNAASTEÓRCASDOMNDOCONIEMPORÂNEO}


meio de decisão do STF, pode aplicar um processo licitatório simplificado, citando também as excludentes dentro da lei, no art. 24 e 25, onde temos a dispensa de licitação no art. 24, ou, a inviabilidade técnica para realizar a licitação no art. 25. O autor chama também atenção aos serviços públicos feitos por concessão ou permissão, que obrigatoriamente são feitos por meio de licitação, ou seja, são os delegatários de serviços públicos, assim os particulares, que desenvolvem a vida pública.

Licitar, segundo Guedes (2014) é em procedimento administrativo obrigatório, feito para que sejam realizadas obras, serviços, alienações, locações, vendas e etc. envolvendo o poder público.

Para que haja uma licitação, segundo o autor, precisamos atentar para a capacidade técnica, econômica e financeira, para que o processo licitatório seja feito com a melhor vantagem levando em conta o custo e o benefício do contrato, respeitando o princípio da isonomia, para a igualdade das partes se sobressair, buscando a proposta mais vantajosa.

Outra saliência importante apresentada pelo autor são os princípios da licitação, que ele separa da seguinte forma.

\footnotetext{
Legalidade; Vincula as regras do Poder Vinculado e do Poder Discricionário, não pode exigir do licitante a condição de habilitação econômica sempre acima da margem do necessário.

Impessoalidade; diz que o administrador público deve usar os critérios objetivos, ou seja, o que está prescrito em lei.

Moralidade; deve trabalhar com critérios éticos e morais.

Probidade; Lei 81429/99 que diz sobre a lei de improbidade administrativa.

Igualdade; Chamado também de isonomia, trabalhado no artigo terceiro, diz respeito sobre o desempate.

Publicidade; os interessados devem ter acesso e controle através de diário oficial, ou meio de acordo para tal.

Vinculação do instrumento convocatório; segue utilizando em edital publicado em Diário Oficial ou em carta convite. (GUEDES, 2014)
}

Segundo Vasconcelos (2014), esta possibilidade se alia ao objetivo do RDC - Regime Diferencial de Contratação, que visa melhor eficácia e economia para o Estado, que buscará melhor remuneração e particularização dos acordos com o grau de desempenho de cada contrato, uniforme com a satisfação do serviço realizado em vista de quaisquer licitações, a fim de atender o coletivo sempre. 
Para exemplificar, podemos usar em paralelo a construção da cidade de Brasília, na década de 1950, quando não se tinha essa preocupação com os gastos e com a transparência.

Como a construção era vista como prioridade, foram utilizados todos os fundos por conta do tempo e espaço para sua construção, pois o ideal do momento era a excelência, porém, para que essa excelência fosse obtida os cofres públicos gastaram sem controle nenhum, podendo dizer que quase acabaram com os recursos financeiros da época. Se a lei 8.666/93 já estivesse em vigor no período, os gastos seriam muito menores, pois os materiais e afins seriam adquiridos pela proposta mais vantajosa e não pela boca do caixa.

Não há dúvidas da importância das licitações para aquisição de benefícios, trazendo maior segurança e transparência para as contas públicas, assim como a economia das contas públicas, que hoje beneficia toda população, tendo em vista que o dinheiro do cidadão que foi arrecadado na forma de impostos, stá tendo um destino correto, aumentando assim a confiança do cidadão no administrador público.

\section{ANÁLISE DOS RESULTADOS}

Analisamos que a Administração direta e indireta, não possui autonomia de celebrar contratos para bens e serviços, pois a mesma deverá utilizar de um princípio presente na lei, chamado de licitação, que nada mais é do que o processo de segurança a isonomia de condições a todos que desejam realizar o serviço presente na administração pública.

Conforme visto a licitação está resguardada pela lei ํㅜ $8.666 / 93$ com as normativas para que haja um processo transparente e igualitário para a realização do serviço, buscando as condições mais vantajosas para o trabalho e serviço.

Foi observado também, que pouco se sabe da existência desta barreira burocrática denominada de licitação, assim como o motivo dela existir, observada nas literaturas lidas onde mostram que a população em geral, creem que a compra é feita de maneira simplória e rápida, sendo mostrada neste artigo que apenas em dois casos tratados, como dispensa e a licitação pregoaria são demoradas e tem várias vertentes de espaço. 
Em outras palavras, o procedimento administrativo chamado de licitação, é adotado pela Administração Pública para buscar a proposta mais vantajosa para aplicação de contratos onde proporcionem igualdade de condições a todos que podem e servem o objeto da licitação ao poder público. Ainda se falando em lei 8.666/93, podemos desmembrá-la por modalidades, que são elas I - concorrência; II - tomada de preços; III - convite; IV - concurso; e V - leilão.

\section{Quadro 1. Tipos de Licitação}

Fonte: Brasil (1993).

\begin{tabular}{|c|c|c|}
\hline Convite & $\begin{array}{l}\text { Estipula valor máximo para en- } \\
\text { genharia de } 150 \text { mil e para de- } \\
\text { mais bens de serviços o valor vai } \\
\text { para } 80 \text { mil reais. }\end{array}$ & $\begin{array}{l}\text { Aqui a administração é obrigada a con- } \\
\text { vidar no mínimo } 3 \text { licitantes interessa- } \\
\text { das para participar do processo licitató- } \\
\text { rio, não sendo obrigatório ser convi- } \\
\text { dado para participar do convite. Geral- } \\
\text { mente é publicada } 5 \text { dias antes do pro- } \\
\text { cesso. }\end{array}$ \\
\hline $\begin{array}{l}\text { Tomada de } \\
\text { Preço }\end{array}$ & $\begin{array}{l}\text { Estipula valor máximo para en- } \\
\text { genharia de } 1,5 \text { milhão e para } \\
\text { demais serviços } 650 \text { mil reais. }\end{array}$ & $\begin{array}{l}\text { Aqui, o serviço se prende a preço ou a } \\
\text { técnica, em menores qual tipo de licita- } \\
\text { ção deverá ser empregado, depen- } \\
\text { dendo muito do tempo que será publi- } \\
\text { cado seu tempo em diário oficial, geral- } \\
\text { mente leva } 20 \text { dias para realizar o pro- } \\
\text { cesso após a realização da publicação. }\end{array}$ \\
\hline Concorrência & $\begin{array}{l}\text { Estipula valores acima de } 1,5 \mathrm{mi}- \\
\text { lhão para engenharia e para de- } \\
\text { mais bens acima de } 650 \text { mil re- } \\
\text { ais. }\end{array}$ & $\begin{array}{l}\text { Modalidade que abrange todas as ante- } \\
\text { riores e valores acima delas, podendo } \\
\text { levar até } 15 \text { dias para ocorrer o pro- } \\
\text { cesso após sua publicação. }\end{array}$ \\
\hline Leilão & Abrange a venda de bens. & $\begin{array}{l}\text { Edital deve ser publicado com no mí- } \\
\text { nimo de } 15 \text { dias de antecedência do ato } \\
\text { da venda. }\end{array}$ \\
\hline Concurso & $\begin{array}{l}\text { Técnica, essa modalidade é } \\
\text { usada, para pagar um serviço } \\
\text { que não se enquadra em ne- } \\
\text { nhuma das outras modalidades } \\
\text { como por exemplo, um trabalho } \\
\text { artístico. }\end{array}$ & $\begin{array}{l}\text { O edital fica exposto por } 45 \text { dias, pois } \\
\text { exige técnica, não havendo limite para } \\
\text { pagamento. }\end{array}$ \\
\hline Pregão & $\begin{array}{l}\text { 10.520/02. Para compra de bens } \\
\text { e serviços comuns, não havendo } \\
\text { limite de valores. }\end{array}$ & $\begin{array}{l}\text { Não permite técnicas com edital de } 8 \\
\text { dias. }\end{array}$ \\
\hline
\end{tabular}

Cada uma dessas, tem finalidades distintas, para comparar a eficácia delas comparei dois Órgãos, Polícia Militar do Estado de São Paulo e Secretaria Estadual De Educação de São Paulo, preservando seus respectivos batalhões e diretorias, analisando a compra de seus bens e a realização de suas obras olhei em seus portais de transparência onde o batalhão de polícia militar, tinha eficácia e eficiência nos gastos do dinheiro público, onde suas compras vinham, 
por meio de diversas maneiras de verbas, mas a principal era o uso correto e a eficiência das leis, enquanto a SEDUC-SP ainda insiste em usar a lei 8.666/93, onde o processo de compra de um bem ou realização de um serviço pode levar messes, o batalhão de polícia militar consegue realizar a obra dependendo do valor em 15 dias e o pagamento para 30.

Analisei as diferenças, enquanto a SEDUC-SP, não investe em treinamento, a PMESP manda seus policiais que cuidam dos processos licitatórios para cursos e treinamentos de aperfeiçoamento, para aprimoramento do processo, notei em meu levantamento de dados, que muitos gestores não sabiam sobre processos licitatórios, fazendo com que um funcionário de baixo escalão da SEDUC, que tenha passado pela Polícia Militar do Estado de São Paulo, sabia mais de processo licitatório do que seus superiores e supervisores, tendo que ensinar processos básicos como consulta a bolsa eletrônica de compras (BEC) e consulta de empresas, pois ainda se comprava de empresas que não poderiam vender para o Estado, notando que grande parte dos processos administrativos (processo de exoneração) da SEDUC-SP por meio deste assunto, são por imperícia.

Quadro 2. Quantidade de obras 2018 X tempo para realização em meses

\begin{tabular}{|l|l|l|l|}
\hline \multicolumn{2}{|c|}{ SEDUC-SP diretoria de ensino X } & \multicolumn{2}{c|}{ PMESP batalhão $\mathrm{Y}$} \\
\hline Obras & Meses & Obras & Meses \\
\hline 52 & 17 & 148 & 10 \\
\hline
\end{tabular}

Fonte: Elaborado para esta pesquisa.

No ano de 2018, podemos observar que houve um melhor aproveitamento do dinheiro público por parte da PMESP, salientando que o batalhão é o menor dos órgãos, comparado a uma escola da diretoria, sendo assim, recebe menos verba do que a diretoria, porém, teve melhor orientação para compras. 
Gráfico 1. Compras

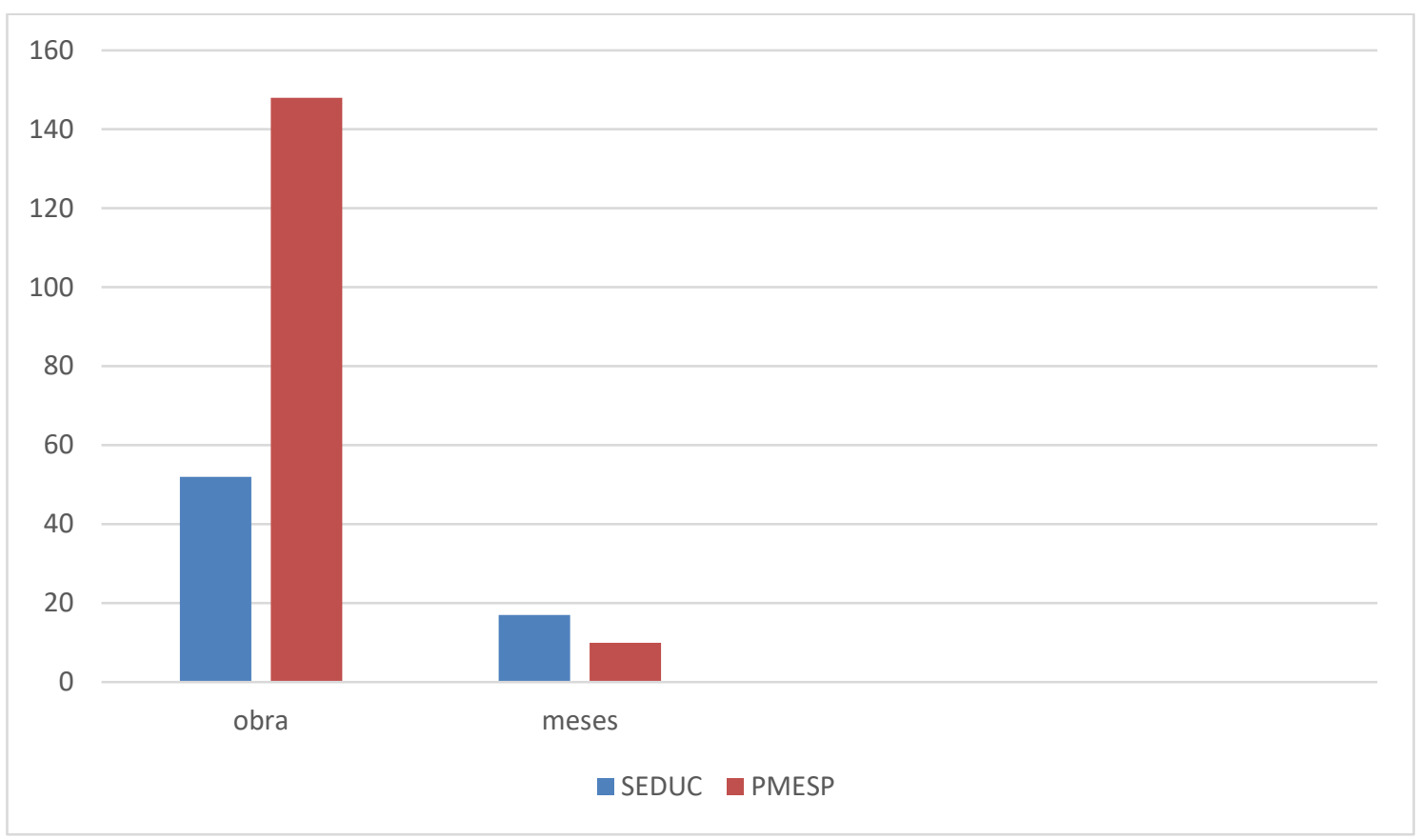

Fonte: Elaborado para esta pesquisa.

Cito por exemplo a compra que acompanhei de papel sulfite, enquanto a PMESP assinou contrato com a empresa de impressoras LEXXMARK, a SEDUC-SP comprou folhas de sulfite e tonner a parte para configuração de suas pastas pessoais, cada troca e conserto para SEDUC, sai por volta de 150 reais por mês por máquina, fora a manutenção das maquinas que dariam mais 400 por ano, a PMESP paga por 20 máquinas em torno de 3 mil e 500 reais com suprimento de sulfite e tonner, além das manutenções garantidas.

Conforme a lei 8666/93, não é aplicado o princípio fundamental dela pelos órgãos públicos, a aquisição da proposta mais vantajosa e não dá mais barata, tendo esse cuidado pelos órgãos.

Exemplificando, colocarei um exemplo de engenharia, onde uma escola de São Paulo teve uma de suas salas atingida por uma árvore e parte do telhado do restante da escola foi prejudicada, para a elaboração do edital, levaram-se 15 dias, para publicação mais 5 , mais 5 para as empresas comparecerem ao convite e 6 meses de obras enquanto no mesmo período de chuvas o mesmo ocorreu em um batalhão especializado da Polícia Militar do Estado de São Paulo, onde 
utilizaram de um sistema chamado de Dispensa de Licitação, foi realizado um projeto básico, comparecem 3 empresas para verificar qual possui o menor preço com melhor benefício, assim, a melhor proposta leva o serviço, após a realização do serviço a empresa emite a nota fiscal e por meio desta nota fiscal o Estado paga em 30 dias corridos, ou seja, a empresa se sente na obrigação de terminar rápido e com qualidade, pois quaisquer problema derivados na obra todos envolvidos são sancionados e não poderão mais prestar serviços ao Estado.

\section{CONSIDERAÇÕES FINAIS}

De maneira límpida, notamos que para a Gestão Pública se responsabilizar pela distribuição do dinheiro público e pela garantia do andamento da máquina pública, para que haja um entendimento mútuo entre a população e o Estado foi proposta a lei $n^{\circ} 8,666 / 93$, que preconiza e orienta as maneiras pelas quais o dinheiro público deve ser administrado e gasto. Esta lei está empregada a contratação de serviços, obras, materiais e demais serviços que a Administração Pública necessite para que haja a sobrevivência dos serviços públicos.

As preconizações impostas pelas Leis de Licitação visam mostrar ao administrador o que ele pode ou não pode realizar com o dinheiro arrecadado pela Administração Pública, a fim de que encontrem a proposta de contratação de bens e serviços mais favorável ao Estado, de maneira que elucide os gastos públicos ao interesse público.

Podemos concluir que a Constituição Federal impôs uma sequência de regras que devem ser obedecidas para aquisição de produtos e serviços, denominada de licitação, que busca o melhor preço e serviço, num conjunto de propostas apresentadas a Administração Pública, que deverá verificar qual a mais vantajosa.

Um dos problemas encontrados é a formulação destas licitações, geralmente feitas por setores que não tem conteúdo técnico para analisar as compras e acompanhar os procedimentos licitatórios, o que faz com que as aquisições sejam realizadas por profissionais que não conhecem o dia a dia do setor e geralmente não tem contato com o produto.

Por serem temas complexos, podemos também notar a má compreensão em editais publicados em Diário Oficial e em consequência a aquisição de produtos e serviços impróprios ou de má qualidade. 
Podemos dizer que o objeto declarado em contratos tem amparo das legislações como a Lei ํㅛ 8.666/93, atendendo diretamente projetos públicos com especificações dadas em projetos básicos e editais, tendo que seguir as atividades conforme especificado pela autora Daniela Cerri Junqueira (2013).

\footnotetext{
1) contratação indireta de pessoal, a qualquer título;

2) gerenciamento ou operação de serviços de saúde;

3) aquisição de gêneros alimentícios;

4) contratação de serviços técnicos ou administrativos desvinculados de projetos acadêmicos específicos e definidos; (JUNQUEIRA, 2013)
}

Além disso, vemos que a população desconhece os trâmites legais, esperando sempre por obras "faraônicas", as quais se gastam milhões dos cofres por isso que a Lei 8.666/93 foi criada, para transparecer os gastos públicos demonstrando seus usos e dando respostas ao Poder Público.

\section{REFERENCIAS BIBLIOGRÁFICAS}

BRASIL. Constituição da República Federativa do Brasil de 1988 de 5 de outubro de 1988.

BRASIL. Lei n. 8.666, de 21 de junho de 1993.

CHAVES, Luiz Cláudio de Azevedo. Curso Prático de Licitações: Os Segredos da Lei no 8666/93. 1. ed. São Paulo: Lumen Júris, 2011.

GARCIA. Flavio Amaral. Licitações e contratos administrativos. Casos e polêmicas. 3. ed. Rio de Janeiro: Lumen Juris, 2010.

JUNQUEIRA, Daniela Cerri. Licitações e contratos da administração pública. São João da Boa Vista: Lumen Júris, 2013.

JUSTEN FILHO, M. Comentários à Lei de Licitações e Contratos Administrativos. 11 ed. São Paulo: Dialética, 2005.

MAURER, Daniela Ferreira. Revisão Narrativa em Licitações na Saúde Pública. São Francisco de Paula: Lumen Júris, 2013.

PALAVÉRI, Marcelo. Licitações Públicas: Comentários e notas às súmulas e à jurisprudência do Tribunal de Contas do Estado de São Paulo. Belo Horizonte: Fórum, 2009. 